\title{
FAKTOR-FAKTOR YANG BERHUBUNGAN DENGAN PEMBERIAN ASI EKSKLUSIF PADA SALAH SATU DESA DI KABUPATEN TANGGAMUS
}

\author{
Senja Rathmaliza Putri*, Helmi Yenie** \\ *Alumnus Jurusan Kebidanan Poltekkes Tanjungkarang \\ **Dosen Jurusan Kebidanan Poltekkes Tanjungkarang
}

\begin{abstract}
Cakupan pemberian ASI Eksklusif di Indonesia masih jauh dari target 80\% yaitu 54.3\%(2014). Hasil studi pendahuluan yang dilakukan tanggal 12 November 2016 di Desa Air Kubang,Kecamatan Air Naningan dengan teknik wawancara kepada 10 ibu menyusui bahwa didapatkan (30\%) ibu menyusui memberikan ASI eksklusif dan sedangkan (70\%) lainnya tidak memberikan ASI Eksklusif dan belum diketahui faktor-faktor yang berhubungan dengan Pemberian ASI Eksklusif di Pos Kesehtan Desa Air Kubang Kecamatan Air Naningan Kabupaten Tanggamus Tahun 2017. Tujuan penelitian ini adalah untuk mengetahui faktor-faktor yang berhubungan dengan pemberian ASI Eksklusif ditinjau dari Pendidikan, Pengetahuan, Sikap, Pekerjaan, Status Ekonomi. Penelitian ini merupakan penelitian analitik dengan pendekatan cross sectional, dilakukan pada bulan Februari-April 2017. Populasi dalam penelitian ini adalah seluruh Ibu yang mempunyai bayi berusia 6-12 bulan di Pos Kesehatan Desa Air Kubang Kecamatan Air Naningan sebanyak 58 orang.Sampelnya adalah total populasi.Data yang digunakan adalah data primer.Alat yang digunakan untuk mengambil data adalah kuesioner dengan cara angket, Analisa data menggunakan Univariat dan Bivariat dengan uji statistik menggunkan Chi Square. Hasil penelitian menyimpulkan dengan 58 responden, di dapatkan hasil : Pendidikan $(p$ value $=0,013)$, Pengetahuan $(p$ value $=0,002)$, Sikap $(p$ value $=0,001)$,Status Ekonomi $(p$ value $=0,001)$,Pekerjaan $(p$ value=0,002). Peneliti menyarankan agar dapat dilakukan penyuluhan pada Ibu-Ibu hamil dengan menggiatkan Kader, Dukun, Pamong Desa serta Tenaga Kesehatan untuk terus memberikan informasi kepada Ibu-Ibu tentang ASI Eksklusif di Posyandu, Pos Kesehatan Desa dan Tempat-Tempat strategis lainnya.
\end{abstract}

Kata Kunci: Ibu Menyusui, ASI Eksklusif

\section{LATAR BELAKANG}

Menurut WHO, pada tahun 2013 AKB di dunia 34 per 1.000 kelahiran hidup, AKB di negara berkembang 37 per 1.000 kelahiran hidup dan AKB di negara maju 5 per 1.000 kelahiran hidup. AKB di Asia Timur 11 per 1.000 kelahiran hidup, Asia Selatan 43 per 1.000 kelahiran hidup, Asia Tenggara 24 per 1.000 kelahiran hidup dan Asia Barat 21 per 1.000 kelahiran hidup (WHO, 2014). Angka kematian bayi (AKB) di Provinsi Lampung berdasarkan hasil Survey Demografi Kesehatan Indonesia (SDKI) tahun 2002 2012 trendnya menunjukkan kecenderungan menurun. Berdasarkan laporan SDKI tahun 2012, Angka Kematian Bayi sebesar 30 per 1000 Kelahiran hidup (Dinkes Provinsi Lampung, 2013). Tingginya AKB di Indonesia, disebabkan oleh beberapa faktor, antara lain disebabkan karena kelahiran prematur, infeksi saat kelahiran,rendahnya gizi saat kelahiran, kelainan bawaan (kongenital) serta rendahnya pemberian ASI segera setelah bayi lahir (inisiasi ASI) dan pemberian ASI ekslusif selama 6 bulan pertama kehidupan bayi. Inisiasi ASI dan pemberian ASI ekslusif berperan penting dalam mengurangi angka kematian bayi di Indonesia, hingga diharapkan target MDGs pada tahun 2015 dapat tercapai (Ginanjar, 2010).

Menurut UNICEF pada tahun 2013, dari 136,7 juta bayi lahir diseluruh dunia dan hanya $32,6 \%$ dari mereka yang disusui secara eksklusif dalam 6 bulan pertama. Sedangkan di negara industri, bayi yang tidak diberi ASI Eksklusif lebih besar meninggal dari pada bayi yang diberi ASI Eksklusif. Sementara di negara berkembang hanya $39 \%$ ibu-ibu yang 
memberikan ASI Eksklusif (UNICEF, 2013). Pedoman internasional yang menganjurkan pemberian ASI eksklusif selama 6 bulan pertama didasarkan pada bukti ilmiah tentang manfaat ASI bagi daya tahan hidup bayi, pertumbuhan, dan perkembangannya. ASI memberikan semua energi dan gizi (nutrisi) yang dibutuhkan oleh bayi selama 6 bulan pertama setelah kelahirannya. Pemberian ASI eksklusif dapat mengurangi tingkat kematian bayi yang dikarenakan berbagai penyakit yang menimpanya serta mempercepat pemulihan bila sakit dan membantu menjarangkan kelahiran (Prasetyono, 2009). Berdasarkan pencatatan dan pelaporan dari sarana kesehatan di Provinsi Lampung, tampak bahwa cakupan pemberian ASI Ekslusif pada tahun 2011 adalah sebesar 29,24\% dengan angka target $60 \%$, sedangkan pada tahun 2012 angka cakupan tercatat sebesar $30,05 \%$ dengan target sebesar $80 \%$ data tersebut tampak bahwa cakupan ASI Ekslusif di Provinsi Lampung belum mencapai target yang ditetapkan provinsi (Dinkes Provinsi Lampung, 2013).

Kabupaten Tanggamus membawahi beberapa Kecamatan, salah satunya adalah Kecamatan Air Naningan. Berdasarkan data di Puskesmas Rawat Inap Air Naningan, cakupan pemberian ASI Eklusif hanya $66 \%$ atau dari 412 bayi hanya 272 bayi yang menyusui secara ekslusif sedangkan di Pos Kesehatan Desa Air Kubang cakupan ASI Eklusif sebesar 50\% dengan urutan terakhir dari 10 Desa di kecamatan Air Naningan (Puskesmas Rawat Inap Air Naningan, 2015).

Desa Air Kubang Kecamatan Air Naningan berada di wilayah kabupaten Tanggamus dan berada $45 \mathrm{~km}$ dari pusat kabupaten Tanggamus. Jumlah tenaga kesehatan perempuan yakni 1 bidan desa dan 1 bidan praktik swasta,berdasarkan data cakupan bayi pada November 2016 didapatkan jumlah bayi sebanyak 58 bayi.

Berdasarkan hasil studi pendahuluan yang dilakukan tanggal 12 November 2016 di Desa Air Kubang, Kecamatan Air Naningan dengan teknik wawancara kepada $10 \mathrm{ibu}$ menyusui bahwa didapatkan
3 (30\%) ibu menyusui memberikan ASI eksklusif dan sedangkan $7(70 \%)$ lainnya tidak memberikan ASI eksklusif dikarenakan berbagai faktor, antara lain adalah pengaruh sosial budaya (memberikan madu, pisang, pepaya pada bayi), produksi ASI kurang, kesulitan bayi dalam menghisap, keadaan puting susu ibu yang tidak menunjang, ibu bekerja, keinginan untuk disebut modern dan pengaruh iklan/promosi pengganti ASI.

\section{METODE}

Rancangan penelitian ini menggunakan Study Analitik dengan pendekatan cross sectional terhadap ibu menyusui yang mempuyai bayi berusia 612 bulan di Desa Air Kubang Kecamatan Air Naningan Kabupaten Tanggamus. Populasi dalam penelitian ini adalah seluruh Ibu yang mempunyai bayi berusia lebih dari 6-12 bulan di Pos Kesehatan Desa Air Kubang Kecamatan Air Naningan Kabupaten Tanggamus. Sampel dalam penelitian ini adalah total populasi yaitu berjumlah 58 orang dengan kriteria inklusi dan eklusi. Intsrumen yang digunakan dalam penelitian ini berupa kuesioner. Cara ukur yang digunakan adalah dengan observasi data primer yang langsung diambil dari responden. Analisa univariat bertujuan untuk menjelaskan atau mendeskripsikan karakteristik setiap variabel penelitian, sesuai dengan tujuan penelitian ini yaitu untuk mengetahui gambaran faktor yang faktor-faktor yang berhubungan dengan pemberian ASI Eksklusif di Pos Kesehatan Desa Air Kubang Kecamatan Air Naningan Kabupaten Tanggamus Tahun 2017, berdasarkan: faktor tingkat pendidikan, pengetahuan ibu, sikap ibu menyusui, dan status ekonomi, dan pekerjaan ibu menyususi. Analisis bivariat pada penelitian ini variabel dependen dan independen dibuat dalam data kategorik, maka uji yang digunakan adalah ChiSquare. Penelitian ini dilakukan dari Bulan Februari sampai Bulan April tahun 2017. 
HASIL

\section{Analisis Univariat}

Tabel 1: Distribusi Frekuensi Tingkat Pendidikan Ibu

\begin{tabular}{lcc}
\hline \multicolumn{1}{c}{ Pendidikan } & f & $\%$ \\
\hline Rendah & 46 & 79,3 \\
\hline Tinggi & 12 & 20,7 \\
\hline Jumlah & 58 & 100 \\
\hline
\end{tabular}

Berdasarkan data di atas,didapatkan hasil responden yang berpendidikan rendah sebanyak 46 responden $(79,3 \%)$.

Tabel 2: Distribusi Frekuensi Pengetahuan Ibu Menyusui

\begin{tabular}{lcc}
\hline \multicolumn{1}{c}{ Pengetahuan } & f & $\%$ \\
\hline Kurang & 39 & 67,2 \\
\hline Baik & 19 & 32,8 \\
\hline Jumlah & 58 & 100 \\
\hline
\end{tabular}

Berdasarkan data di atas,didapatkan hasil responden yang berpengetahuan kurang sebanyak 39 responden $(67,2 \%)$.

Tabel 3: Distribusi Frekuensi Sikap Ibu Menyusui

\begin{tabular}{|c|c|c|}
\hline Sikap & $\mathrm{f}$ & $\%$ \\
\hline Positif & 23 & 39,7 \\
\hline Negatif & 35 & 60,3 \\
\hline Jumlah & 58 & 100 \\
\hline
\end{tabular}

Berdasarkan data di atas,didapatkan hasil responden yang bersikap negatif sebanyak 35 responden $(60,3 \%)$.

Tabel 4: Distribusi Frekuensi Status Ekonomi Keluarga Ibu

\begin{tabular}{lcc}
\hline \multicolumn{1}{c}{ Status Ekonomi } & f & $\%$ \\
\hline Rendah & 35 & 60,3 \\
\hline Tinggi & 23 & 39,7 \\
\hline Total & 58 & 100 \\
\hline
\end{tabular}

Berdasarkan data di atas,didapatkan hasil responden yang berpemghasilan rendah sebanyak 35 responden $(60,3 \%)$.
Tabel 5: Distribusi Frekuensi Pekerjaan Ibu Menyusui

\begin{tabular}{lcc}
\hline \multicolumn{1}{c}{ Pekerjaan } & $\mathrm{f}$ & $\%$ \\
Bekerja & 22 & 37,9 \\
Tidak Bekerja & 36 & 62,1 \\
Jumlah & 58 & 100 \\
\hline
\end{tabular}

Berdasarkan data diatas,didapatkan hasil responden yang tidak bekerja sebanyak 36 responden $(62,1 \%)$.

\section{Analisa Bivariat}

Tabel 6: Hubungan Pendidikan Ibu dengan Pemberian ASI Ekslusif

\begin{tabular}{|c|c|c|c|c|}
\hline \multirow[t]{2}{*}{ Pendidikan } & \multicolumn{2}{|c|}{$\begin{array}{c}\text { Pemberian ASI } \\
\text { Eksklusif }\end{array}$} & \multirow{2}{*}{$\begin{array}{c}\mathrm{p} \\
\text { value }\end{array}$} & \multirow{2}{*}{$\begin{array}{c}\text { OR } \\
(95 \% \mathrm{C})\end{array}$} \\
\hline & Tidak & $\mathrm{Ya}$ & & \\
\hline Rendah & $\begin{array}{c}22 \\
(47,8 \%)\end{array}$ & $\begin{array}{c}24 \\
(52,2 \%) \\
\end{array}$ & & \\
\hline Tinggi & $\begin{array}{c}1 \\
(8,3 \%) \\
\end{array}$ & $\begin{array}{c}11 \\
(91,7 \%)\end{array}$ & 0,013 & 10.083 \\
\hline Total & $\begin{array}{c}23 \\
(39,7 \%)\end{array}$ & $\begin{array}{c}35 \\
(60,3 \%)\end{array}$ & & \\
\hline
\end{tabular}

Berdasarkan tabel, diketahui bahwa pada responden yang berpendidikan rendah terdapat 46 orang $(79,3 \%), 24$ orang (52,2\%) memberikan ASI Eksklusif dan pada responden yang berpendidikan tinggi terdapat 12 orang $(20,7,0 \%), 11$ orang $(91,7 \%)$ memberikan ASI Ekslusif. Nilai OR=10,083 yang berarti kasus Pemberian ASI Ekslusif terjadi pada responden yang berpendidikan tinggi sebesar 10,083 kali dibandingkan pada responden yang berpendidikan rendah.

Tabel 7: Hubungan Pengetahuan Ibu dengan Pemberian ASI Ekslusif

\begin{tabular}{|c|c|c|c|c|}
\hline \multirow{3}{*}{ Pengetahuan } & \multicolumn{2}{|c|}{ Pemberian ASI } & \multirow{3}{*}{$\mathrm{p}$ value } & \multirow{3}{*}{$\begin{array}{c}\text { OR } \\
(95 \% \mathrm{CI})\end{array}$} \\
\hline & \multicolumn{2}{|c|}{ Eksklusif } & & \\
\hline & Tidak & $\mathrm{Ya}$ & & \\
\hline \multirow{2}{*}{ Kurang } & 21 & 18 & \multirow{4}{*}{0,002} & \multirow{4}{*}{9,917} \\
\hline & $(53,8 \%)$ & $23,5 \%)$ & & \\
\hline Baik & $\begin{array}{c}2 \\
(10,5 \%)\end{array}$ & $\begin{array}{c}17 \\
89,5 \%)\end{array}$ & & \\
\hline Total & $\begin{array}{c}23 \\
(39,7 \%)\end{array}$ & $\begin{array}{c}35 \\
60,3 \%)\end{array}$ & & \\
\hline
\end{tabular}

Berdasarkan tabel, maka diketahui bahwa pada responden yang yang 
berpengetahuan kurang terdapat 39 orang $(67,2 \%), 21$ orang $(53,8 \%)$ Tidak memberikan ASI Ekslusif dan pada responden yang berpengetahuan baik terdapat 19 orang $(32,8 \%), 17$ orang $(89,5 \%)$ memberikan ASI Ekslusif. nilai OR=9,917 yang berarti kasus Pemberian ASI Ekslusif terjadi pada responden yang berpengetahuan baik sebesar 9,917 kali dibandingkan pada responden yang berpengetahuan kurang.

Tabel 8: Hubungan Sikap Ibu dengan Pemberian ASI Ekslusif

\begin{tabular}{|c|c|c|c|c|}
\hline \multirow[t]{2}{*}{ Sikap } & \multicolumn{2}{|c|}{$\begin{array}{c}\text { Pemberian ASI } \\
\text { Eksklusif }\end{array}$} & \multirow{2}{*}{$\begin{array}{c}\mathrm{p} \\
\text { value }\end{array}$} & \multirow{2}{*}{$\begin{array}{c}\text { OR } \\
(95 \% \mathrm{CI})\end{array}$} \\
\hline & Tidak & $\mathrm{Ya}$ & & \\
\hline Negatif & $\begin{array}{c}20 \\
(57,1 \%)\end{array}$ & $\begin{array}{c}15 \\
(42,9 \%)\end{array}$ & & \\
\hline Positif & $\begin{array}{c}3 \\
(13,0 \%)\end{array}$ & $\begin{array}{c}20 \\
(87,0 \%)\end{array}$ & 0.001 & 8,889 \\
\hline Total & $\begin{array}{c}23 \\
(39,7 \%)\end{array}$ & $\begin{array}{c}35 \\
(60,3 \%)\end{array}$ & & \\
\hline
\end{tabular}

Berdasarkan tabel, maka diketahui bahwa pada responden yang yang bersikap negatif terdapat 35 orang $(60,3 \%), 20$ orang $(57,1 \%)$ Tidak memberikan ASI Ekslusif dan pada responden yang berpengetahuan baik terdapat 23 orang $(39,77 \%), 20$ orang $(87 \%)$ memberikan ASI Ekslusif. nilai OR=8,889 yang berarti kasus Pemberian ASI Ekslusif terjadi pada responden yang bersikap positif sebesar 8,889 kali dibandingkan pada responden yang bersikap negatif.

Tabel 9: Hubungan Penghasilan Keluarga dengan Pemberian ASI Ekslusif

\begin{tabular}{|c|c|c|c|c|}
\hline \multirow{3}{*}{ Penghasilan } & \multirow{2}{*}{\multicolumn{2}{|c|}{$\begin{array}{c}\text { Pemberian ASI } \\
\text { Eksklusif }\end{array}$}} & \multirow{3}{*}{$\begin{array}{c}\mathrm{p} \\
\text { value }\end{array}$} & \multirow{3}{*}{$\begin{array}{c}\text { OR } \\
(95 \% \mathrm{CI})\end{array}$} \\
\hline & & & & \\
\hline & Tidak & $\mathrm{Ya}$ & & \\
\hline Rendah & $\begin{array}{c}20 \\
(57,1 \%)\end{array}$ & $\begin{array}{c}15 \\
(42,9 \%)\end{array}$ & \multirow{3}{*}{0.001} & \multirow{3}{*}{8,889} \\
\hline Tinggi & $\begin{array}{c}3 \\
(13,0 \%)\end{array}$ & $\begin{array}{c}20 \\
(87,0 \%)\end{array}$ & & \\
\hline Total & $\begin{array}{c}23 \\
(39,7 \%) \\
\end{array}$ & $\begin{array}{c}35 \\
(60,3 \%)\end{array}$ & & \\
\hline
\end{tabular}

Berdasarkan tabel, maka diketahui bahwa pada responden yang yang berpenghasilan rendah terdapat 35 orang $(60,3 \%), 20$ orang $(57,1 \%) \quad$ Tidak memberikan ASI Ekslusif dan pada responden yang berpenghasilan tinggi terdapat 23 orang $(39,7 \%), 20$ orang $(87,0 \%)$ memberikan ASI Ekslusif. nilai $\mathrm{OR}=8,889$ yang berarti kasus Pemberian ASI Ekslusif terjadi pada responden yang berpenghasilan tinggi sebesar 8,889 kali dibandingkan pada responden yang berpenghasilan rendah.

Tabel 10: Hubungan Pekerjaan Ibu dengan Pemberian ASI Ekslusif

\begin{tabular}{|c|c|c|c|c|}
\hline \multirow{2}{*}{ Pekerjaan } & \multicolumn{2}{|c|}{$\begin{array}{c}\text { Pemberian ASI } \\
\text { Eksklusif }\end{array}$} & \multirow{2}{*}{$\mathrm{p}$ value } & \multirow{2}{*}{$\begin{array}{c}\text { OR } \\
(95 \% \mathrm{CI})\end{array}$} \\
\hline & Tidak & $\mathrm{Ya}$ & & \\
\hline Tidak Bekerja & $\begin{array}{c}20 \\
(55,6 \%)\end{array}$ & $\begin{array}{c}16 \\
(44,4 \%)\end{array}$ & \multirow{3}{*}{0.002} & \multirow{3}{*}{7,917} \\
\hline Bekerja & $\begin{array}{c}3 \\
(8,7 \%)\end{array}$ & $\begin{array}{c}19 \\
(86,4 \%)\end{array}$ & & \\
\hline Total & $\begin{array}{c}23 \\
(39,7 \%)\end{array}$ & $\begin{array}{c}35 \\
(60,3 \%)\end{array}$ & & \\
\hline
\end{tabular}

Berdasarkan tabel, maka diketahui bahwa pada responden yang yang tidak bekerja terdapat 36 orang $(62,1 \%), 20$ orang $(55,6 \%)$ Tidak memberikan ASI Ekslusif dan pada responden yang bekerja terdapat 22 orang $(37,9 \%), 19$ orang $(86,5 \%)$ memberikan ASI Ekslusif. nilai OR=7,917 yang berarti kasus Pemberian ASI Ekslusif terjadi pada responden yang tidak bekerja sebesar 7,917 kali dibandingkan pada responden yang bekerja.

\section{PEMBAHASAN}

\section{Hubungan Tingkat Pendidikan dengan Pemberian ASI Ekslusif}

Hasil penelitian ini menemukan bahwa responden yang tidak memberikan ASI Eksklusif,memiliki pendidikan yang rendah yaitu sebesar 79,3\%. Hasil uji statistik menggunakan Chi Square didapat $P$ Value $=0.013$ berarti ada hubungan yang signifikan antara pendidikan dengan pemberian ASI Eksklusif.

\section{Hubungan Pengetahuan Ibu dengan Pemberian ASI Ekslusif}

Hasil penelitian ini menemukan bahwa responden yang memberikan ASI 
Eksklusif,memiliki pengetahuan yang baik yaitu sebesar 67,2 \%. Hasil uji statistic menggunakan Chi Square didapat $P$ Value 0.002 berarti ada hubungan yang signifikan antara pengetahuan dengan pemberian ASI Eksklusif.

\section{Hubungan Sikap Ibu dengan Pemberian ASI Ekslusif}

Hasil penelitian ini menemukan bahwa responden yang tidak memberikan ASI Eksklusif,memiliki sikap yang negatif yaitu sebesar 57,1 \%. Hasil uji statistik menggunakan Chi Square didapat p value 0.001 berarti ada hubungan yang signifikan antara sikap Ibu dengan pemberian ASI eksklusif.

\section{Hubungan Status Ekonomi Keluarga dengan Pemberian ASI Ekslusif}

Hasil penelitian ini menemukan bahwa responden yang tidak memberikan ASI Eksklusif memiliki status ekonomi keluarga yang rendah yaitu sebesar $57,1 \%$. Hasil uji statustic menggunakan Chi Square didapat $P$ Value 0.001 berarti ada hubungan yang signifikan antara tingkat ekonomi dengan pemberian ASI Eksklusif.

\section{Hubungan Pekerjaan Ibu dengan Pemberian ASI Ekslusif}

Hasil penelitian ini menemukan bahwa responden yang tidak memberikan ASI Eksklusif tidak bekerja yaitu sebesar $55,6 \%$. Hasil uji statistic menggunakan
Chi Square didapat P Value 0.002 berarti ada hubungan yang signifikan antara pekerjaan

\section{KESIMPULAN}

Hasil penelitian menyimpulkan bahwa ada hubungan pendidikan, pengetahuan, sikap, status ekonomi, hubungan keluarga dan pekerjaan Ibu menyusui dengan pemberian ASI Eksklusif. Selanjutnya penulis menyarankan agar dapat dilakukan penyuluhan pada Ibu-Ibu hamil dengan menggiatkan Kader, Dukun, Pamong Desa serta Tenaga Kesehatan untuk terus memberikan informasi kepada Ibu-Ibu tentang ASI Eksklusif di Posyandu, Pos Kesehatan Desa dan Tempat-Tempat strategis lainnya.

\section{DAFTAR PUSTAKA}

Dinas Kesehatan Kabupaten Tanggamus, Profil Kesehatan Kabupaten Tanggamus, 2014.

Kementrian Kesehatan RI. Profil Kesehatan Indonesia Tahun 2014, Jakarta.

Prasetyono, Dwi Sunar.2009.Buku Pintar ASI Eksklusif.Yogyakarta:Diva Press 